\title{
Primer número de la revista Espiral, revista de geografía y ciencias sociales
}

\author{
César Germaná Cavero \\ Universidad Nacional Mayor de San Marcos
}

La revista ESPIRAL está dirigida a la academia y al público en general. Buscamos promover la producción académica en torno a la geografía y las ciencias sociales y convertirnos en un espacio de diálogo, reflexión y encuentro. Así también, esperamos debatir posturas teóricas, desde las más diversas corrientes del pensamiento, con un principio de solidaridad, equidad y reciprocidad en los intercambios de saberes. El proyecto busca dar cabida al conocimiento proveniente del saber popular, de movimientos y organizaciones sociales, desde las constantes luchas por la defensa del territorio y el buen vivir.

Desde nuestra perspectiva planteamos la necesidad de desarrollar una ciencia social crítica. Si bien esta manera de abordar la realidad histórico social surge en Europa en los siglos XIX y XX, como consecuencia del profundo malestar e inconformismo de las clases explotadas y dominadas por el capital respecto al incumplimiento de las principales promesas de la modernidad: el logro de la igualdad, de la libertad y la solidaridad, en América Latina tiene un suelo muy fértil para su desarrollo. El científico social portugués Boaventura de Sousa Santos considera al pensamiento crítico como aquel que "no reduce la 'realidad' a lo que existe" sino que, más bien, la considera como "un campo de posibilidades" y su tarea consiste en "definir y ponderar el grado de variación que existe más allá de lo empíricamente dado" (Santos, 2003: 26). Nuestra orientación se diferencia de las ciencias sociales celebratorias de la modernidad y del capitalismo, que asumen la "neutralidad valorativa" del científico social, y consideramos al pensamiento crítico en un claro derrotero ético y político. Buscamos no aceptar al ser como el deber ser, según la propuesta de la ciencia social positivista, sino que planteamos la imperiosa exigencia de la transformación del ser por obra del deber ser. Nos desenvolvemos en el sentido del pensamiento crítico como lo habían señalado con precisión los pensadores de la Escuela de Frankfurt Th. Adorno y M. Horkheimer: "La ciencia puede ser algo más que la simple duplicación de lo real en el pensamiento, sólo si está impregnada del espíritu de la crítica. Explicar la realidad significa siempre romper el cerco mágico de la duplicación. Crítica no significa aquí subjetivismo, sino confrontación de la cosa con su propio concepto. Lo dado se ofrece sólo a una visión que lo considere desde el punto de vista de un verdadero interés: de una sociedad libre, de un Estado justo, del desarrollo de lo humano. Y el que no compara las cosas humanas con lo que ellas quieren significar las ve, en definitiva, en forma no sólo parcial, sino, además, falsa" (Adorno y Horkheimer, 1971: 22). Estamos comprometidos con una ciencia social orientada en el sentido de la tradición del pensamiento crítico -que supone el desmantelamiento del mito de la "neutralidad valorativa"-, pues debemos reflexionar simultáneamente en términos intelectuales, morales y políticos. 
En América Latina el pensamiento crítico no sería fructífero si no se planteara la tarea de la descolonización del saber de la hegemonía eurocéntrica. Se trata -estamos convencidos- de una empresa que implica un enorme desafío para lograr una profunda reestructuración de la ciencia social que contribuya de manera efectiva a la lucha por alcanzar una sociedad más democrática y más igualitaria. En esta tentativa se estarían dando las condiciones para la emergencia de una perspectiva de conocimiento alternativa a la del eurocentrismo.

Proponemos abrir un amplio debate para superar los estrechos límites que han fracturado las ciencias sociales en disciplinas, que las convirtieron en compartimentos estancos. Buscamos alcanzar una creciente unificación de las disciplinas sociales que haga posible una única ciencia social. Desde esta perspectiva unidisciplinaria los estudios sobre la realidad histórico-social serían más productivos que los estudios interdisciplinarios o multidisciplinarios, que son insuficientes para dar cuenta de la complejidad de la vida social, pues la ultraespecialización disciplinaria que las ciencias sociales han estado padeciendo ha sido particularmente improductiva. Planteamos el reto de debatir la posibilidad de lograr la construcción de una única ciencia social, donde la especialización sea trabajada por problemas y no como campos arbitrariamente definidos, como lo muestran los trabajos que publicamos en nuestro primer número. La disciplinarización con la que se construyó históricamente las ciencias sociales en Europa y en Estados Unidos en la segunda mitad del siglo XIX no tiene en la actualidad ningún fundamento epistemológico o teórico válido. La profunda revolución epistemológica que estamos viviendo que proviene de las ciencias de la complejidad, de la teoría de los sistemas, de la mundialización de las relaciones sociales y de la emergencia de las estructuras de saber de los pueblos originarios lleva necesariamente a que solamente podamos comprender cabalmente la sociedad humana desde una perspectiva holística y utopística.

Con esta preocupaciones en el aprendizaje de estos años, decidimos sacar adelante una revista electrónica, donde el empleo de software libre (tanto para alojar la revista en la web como para el diseño de los artículos) y la alianza institucional que permita viabilizar el proyecto y destinar nuestros escasos recursos materiales a tareas como corrección de estilo. Así, con el proyecto ESPIRAL buscamos posicionar a las ciencias sociales y a la geografía como una actividad intelectual productora de conocimientos y preocupada por lo que actualmente sucede en los territorios del Perú, de América Latina y el mundo y de su futuro. 